\title{
Diário de Bitita: a autobiografia ensaística de Carolina Maria de Jesus
}

\author{
Bitita's diary: the essayistic autobiography \\ of Carolina Maria de Jesus \\ Diario de Bitita: la autobiografía ensayística \\ de Carolina Maria de Jesus \\ Deise Quintiliano Pereira*
}

\section{Resumo}

Publicado postumamente, o Diário de Bitita integra o conjunto de escritos memorialísticos de Carolina Maria de Jesus. O presente estudo propõe analisar o texto autobiográfico baseado nas recordações de infância da autora pelo viés de seu aspecto ensaístico. Nossa proposta é demonstrar de que modo a narrativa configura Bitita como uma porta-voz improvável de Carolina, sobretudo a partir das sentenças alegóricas e parabólicas vociferadas pela menina contra a sociedade brasileira que a humilha e oprime.

Palavras-chave: Carolina Maria de Jesus, Diário de Bitita, autobiografia, ensaio.

\section{Abstract}

Published posthumously, Bitita's diary comprises the collection of Carolina Maria de Jesus' memoirs. The present study aims to analyze the autobiographical writings based on the author's childhood recollections through the lenses of their essay-like aspect. Our proposal is to demonstrate the way through which the narrative establishes Bitita as an unlikely spokeswoman for Carolina, stemming particularly from the allegorical and parabolic utterances voiced by the girl against the Brazilian society which humiliates and oppresses her.

Keywords: Carolina Maria de Jesus, Bitita's Diary, autobiography, essay.

\section{Resumen}

Publicado póstumamente, el Diario de Bitita integra el conjunto de escritos memorialistas de Carolina Maria de Jesus. El presente estudio se propone analizar el texto autobiográfico basado en los recuerdos de infancia de la autora por el sesgo de su aspecto ensayístico. Nuestra propuesta es demostrar de qué modo la narrativa configura a Bitita como una portavoz improbable de Carolina, sobre todo a partir de las sentencias alegóricas y parabólicas vociferadas por la niña contra la sociedad brasileña que la humilla y la oprime.

Palabras-clave: Carolina Maria de Jesus, Diario de Bitita, autobiografia, ensayo.

\section{O ensaio}

Do ponto de vista etimológico, o vocábulo "ensaio" encontra sua origem na palavra latina exagium, na medida em que se associa ao exame valorativo de metais. Também em exagium repousa a raiz da palavra francesa essai, que remete ao sentido de experimento ou prova. Uma terceira acepção evoca uma conexão com o termo clássico ludus, indicando que elaborar um ensaio significa "ensaiar o intelecto", estabelecendo um jogo de ideias.

Outra compreensão possível parte do sentido de gustus, que instaura uma relação entre o ensaio e o ritual em que o degustador ingeria alimentos antes da corte para preservá-la de envenenamentos. Montaigne, aliás, elabora tal consideração ao afirmar que as normas e doutrinas respeitadas são falsas, perigosas, mortais, de onde decorre que o ensaio preservaria

\footnotetext{
* Doutora em Letras Neolatinas e professora da Universidade do Estado do Rio de Janeiro (UERJ), Rio de Janeiro, RJ, Brasil. orcid.org/0000-0002-8018-1846. E-mail: deisequintiliano@uol.com.br
} 
o leitor de tais armadilhas. O ensaio aglutinaria, ademais, uma esfera crítica, haja vista que "todo ensaio deve ser crítico". Como consequência da crítica:

Montaigne irá ensaiar (exagiare) suas ideias, ou seja, vai dissecá-las, analisá-las na tentativa de chegar ao material valioso que elas contêm. O poder simbólico da balança expressa, em Montaigne, a detida e pertinaz análise de uma situação, julgar de modo imparcial, saborear, para então escrever sobre a matéria, assimilando às ideias os seus pesos apropriados. As palavras "balança" e "peso" apontam para algo de natureza empírica, dentro do terreno da prática, o que se mostra a princípio uma antítese à ideia de "julgar" e "examinar", posto que estes últimos se referem a ações inscritas no ambiente da subjetividade. Todavia, o ensaio participa destas duas dimensões, perpassando os dois pontos de vista: o objetivo e o subjetivo, e por tal razão é tarefa de grande dificuldade defini-lo (Lima, 1946, p. 68).

Ainda que a classificação do gênero ensaístico possa ser usada para descrever fenômenos cuja origem remonta à Antiguidade e à Idade Média, a forma moderna estilizada por Michel de Montaigne é a que reverbera de maneira soberana quando abordamos o tema, nos dias atuais. De fato, a aparição da nomenclatura ocorre no ano 1580, momento em que surge, pela primeira vez, os Essais de Messire Michel, seigneur de Montaigne. Nesse contexto: "Montaigne criaria literariamente - segundo se pensa e se diz - não só a palavra ensaio como também um gênero novo: o ensaio" (Lima, 1946, p. 9). O ensaio não se apresenta como um gênero literário menor - tendo presente as complexas reflexões sobre literatura maior e menor colocadas no tabuleiro da crítica teórica na contemporaneidade. Sua alma é o paradoxo, já que sua existência é contraditoriamente ofuscada pelo excesso de difusão, versatilidade, imediatismo e pelo caráter pragmático da comunicação que promove.

Em suma, o ensaio instaura um liame com a tentativa, o experimento, o exercício, a prova. Segundo Alfonso Berardinelli (2011, p. 1): “A escrita com a qual comunicamos pensamentos, juízos, reflexões, interpretações pode se apresentar como um tipo de escrita direta, mas ao mesmo tempo sofisticada e indócil ou, ao contrário, flexível e maleável". No que tange à inventividade construtiva, é possível se depreender que os maiores ensaístas "criaram" e "inventaram" literariamente, sem construir necessariamente um mundo alternativo ao real, antes dialogando com o contexto comunicativo e social do seu tempo: "De Montaigne a Francisco de Sanctis, de Kierkegaard a Orwell, de Simone Weil a Gramsci, observou-se que o ensaísta pode se exprimir alternadamente de maneira idiossincrática ou anárquica, ou tecendo estratégias intelectuais inspiradas por uma "missão" pública, pela necessidade pedagógica e civil" (Berardinelli, 2011, p. 26).

Com efeito, o romance do século XX concedeu uma centralidade estratégica à forma ensaística, expressa sob o modelo da prosa ensaística, na maioria das vezes muito subjetiva, fragmentária, diarística, quase uma escrita para uso pessoal. Nessa via, a prosa de Kafka se articula no aforismo e na parábola e, para além de Montaigne e de Pascal, Nietzsche reflete filosoficamente como grande ensaísta. Por outro lado, a descrição freudiana de inúmeros casos clínicos denuncia que a forma híbrida e mista do ensaio possui uma porosidade que se adéqua à perquirição e descoberta de novos campos de pesquisa. Por essa razão, talvez, uma longa série de grandes críticos literários do século XX como Auerbarch, Adorno, Benjamin, Barthes e Blanchot, mais do que puros cientistas do texto literário, fossem efetivamente ensaístas no sentido mais depurado da expressão.

A exemplo do ensaio, também o romance ensaístico dispensa definições cronotrópicas, descrições de espaço e circunscrição de tempo onde se desenrola a trama uma vez que a "verdade (quando possível) se instala em seus textos como um enigma a desvendar ou como a estrela polar que persegue não como um padrão assente" (Moisés, 2001, p. 87). Transliterando conversas dos personagens ficcionais, no universo literário, traços de oralidade e de polifonia vocais são passíveis de se imporem no ensaísmo com o leitor. O mundo narrativo "concreto" do romance ensaístico não se estrutura sobre qualquer centralidade, definição ou doutrina, embora reflita o caráter alegórico e parabólico da ficção, eivada de crítica de dimensões culturais e sociais.

A pluralidade semântica contida na tipificação do romance ensaístico não é completamente nova posto que está impregnada do que no passado se denominava "romance filosófico". Destarte, é compreensível que textos reflexivos tendam a produzir romances ensaísticos, 
ocupando um território fronteiriço entre "prosa teórica, divagação narrativa e metaficção [espaço onde] parece prudente colocar o ensaio, gênero que encontra apenas uma definição apofática: ele não é isso ou aquilo, mas pode ser todas aquelas outras coisas" (Conceição Júnior, 2017, p. 42).

\section{O diário}

A quase totalidade da produção literária de Carolina Maria de Jesus define-se por seu caráter memorialístico. Obra póstuma, o Diário de Bitita, apelido da menina Carolina, apresenta a singularidade de ter sido publicado primeiramente em francês, em 1982, sob o título de Journal de Bitita - resultado da decisão da autora de entregar, em 1975, seus cadernos a duas jornalistas francesas, que se deslocaram ao Brasil para entrevistá-la. O manuscrito original permanece inédito até 1986, quando a editora Nova Fronteira lança o diário, o qual comporia com Quarto de despejo (1960) e Casa de alvenaria (1961) a trilogia autobiográfica carolineana.

Malgrado o corpus se ofereça às ricas análises sobre a escrita de si, abordaremos a expressiva organização da narrativa sob a forma de um ensaio, pelo descolamento de marcas inerentes à elaboração canônica de um diário - como a ausência de datação e entradas -, pela fuga do rigor do romance histórico, pela substituição da técnica dedutiva da tradição filosófica em favor da alternativa empirista, e, sobretudo, porque no ensaio, como nos ensina Adorno, as recordações e a vida se confundem no resultado final do pensamento.

Carolina Maria de Jesus tornou-se conhecida no cenário nacional e internacional após ter sido descoberta pelo jornalista Audálio Dantas, recentemente falecido (30 de maio de 2018), que a incentivou e possibilitou a publicação de seus diários, primeiramente em pequenos fragmentos veiculados em reportagens na revista O Cruzeiro e, mais tarde, em agosto de 1960, por ocasião do lançamento do livro Quarto de despejo: diário de uma favelada. O sucesso da obra na qual Carolina relata seu cotidiano na favela paulistana do Canindé foi extraordinário, em consonância com o clima populista vigente na sociedade brasileira da virada da década de 1950/60. Investida no papel de mulher negra, pobre, favelada, semianalfabeta, mãe solteira, catadora de lixo, senta-se no trono simbólico da luta contra as injustiças sociais, denunciando a condição existencial do oprimido. $\mathrm{O}$ reconhecimento instantâneo aliado à superexposição lançou a escritora no olho do furacão marcado por problemas, contestações e polêmicas.

Sobre este momento intrincado na vida de Carolina, observa José Carlos Sebe Bom Meihy:

Carolina, evidentemente, padeceu com as mudanças ocorridas em sua vida depois do lançamento de seu primeiro livro. A súbita alteração de padrões de vida e a popularidade a perturbaram. E muito. Sem saber como se comportar, de repente foi-lhe delegado um papel social que não podia desempenhar: ser escritora famosa, mulher requisitada para pronunciamentos e posturas políticas. De sua solidão no recôndito de seu barraco à vida pública havia um caminho que foi cortado pelo padrão externo, desenhado para pessoas treinadas para o desempenho desejado pela sociedade. E também por seus editores, principalmente pelo "parceiro" Audálio Dantas (Meihy, 2004, p. 35).

Cabe observar que às dificuldades somou-se também uma grande conquista: a condição financeira que viabilizaria a compra da sonhada "Casa de Alvenaria", mencionada nas frases conclusivas do Diário: "Rezava agradecendo a Deus e pedindo-lhe proteção. Quem sabe ia conseguir meios para comprar uma casinha e viver o resto dos meus dias com tranquilidade" (Jesus, 2016, p. 206). Sob o sugestivo título de Casa de alvenaria: diário de uma ex-favelada, Carolina de Jesus enfrentaria o período que se seguiu à publicação do primeiro livro, bem como as circunstâncias de escrita desses diários:

$\mathrm{O}$ mercado exigia continuidade, e seria naquele momento ou nunca mais. Carolina, em outro ritmo, teve de dar prosseguimento aos seus diários. Sem a naturalidade do anterior, suas aventuras na Casa de alvenaria equivaliam a uma espécie de segundo capítulo de uma novela folhetinesca. Não resta dúvida de que saiu a toque de caixa, na ânsia de aproveitar a força do Quarto de despejo. Deve ter sido mecânica a repetição da fórmula anterior: entradas por dias, apresentação de Audálio, a mesma casa editorial (Meihy, 2004, p. 35). 
O segundo livro, todavia, mostrou-se incapaz de repetir o triunfo do primeiro. É nesse contexto que, antes de sair de cena no fim de 1963, resistindo à expropriação de seu "capital simbólico", a escritora perseveraria ainda em trilhar as sendas abertas da literatura, editando e publicando, às suas próprias expensas, o romance Pedaços da fome (1963) e a coleção de pensamentos intitulada Provérbios (1963), sem, contudo lograr o êxito pretendido junto ao público. Ao fracasso editorial, combinam-se a frustração pessoal, a decepção com a carreira literária e a profunda amargura determinante na decisão de Carolina de abraçar o ostracismo, mudando-se da cidade para um sítio no campo.

Embora concedesse maior importância a seus poemas, contos e romances, tal movimento traduziria uma estratégia de reflexão e realinhamento da cartografia de seu projeto escritural pelo viés do projeto autobiográfico, conforme esclarece o importante artigo de Daniel da Silva Moreira:

É neste momento da vida de Carolina Maria de Jesus, de transição abrupta, registrada repetidamente em seus diários, após a autora ter sido catapultada do cenário intelectual brasileiro - quando mal começava a compreendê-lo e a integrá-lo -, destituída da posição pela qual lutara durante tanto tempo e sentindo-se explorada e mal entendida por todos, que ela vai se voltar para o passado, recorrer à memória e à recolha de histórias sobre si e sobre sua família. Carolina inicia um processo de releitura e reorganização de seus arquivos pessoais e suas ações nesse sentido vão desde o gesto de copiar e recopiar incessantemente, mesmo que sem consideráveis alterações, seus manuscritos até a significativa atitude de escrever sobre seus textos antigos, como se fizesse de seu texto um palimpsesto (Moreira, 2009, p. 67).

À medida que destrinça os componentes políticos que subjaziam à débâcle da carreira da escritora, o ensaio de Moreira (2009, p. 67) é também fundamental por explicitar que, longe de constituir-se num evento isolado, o crescente declínio da figura de Carolina, sua ascensão e queda têm relação direta com a conjuntura política do Brasil no início dos anos 1960. Nas palavras de Carlos Vogt (1983, p. 205), "O descenso do prestígio de Carolina coincide com o fim do populismo oficial no país e com a virada política do golpe militar". Ademais, Moreira salienta que, de tão fugaz e marcante, a experiência fez com que se associasse à Carolina desta fase a figura de uma Cinderela negra, que, mal alcança o estrelato, já perde seu encanto. E não por acaso, Cinderela negra: a saga de Carolina Maria de Jesus é o título do livro organizado por Robert M. Levine e José Carlos Sebe Bom Meihy, que reúne, além de depoimentos sobre Carolina, dois de seus textos inéditos:

Parece que Carolina elege um projeto em especial ao qual se dedicar no sítio: a redação de suas memórias de infância e adolescência, projeto bem mais complexo que a simples reordenação de algo que já estava escrito. É no momento em que tudo nos levaria a apostar numa desistência total por parte de Carolina de qualquer atividade relacionada à escrita que ela se insurge, mais uma vez por meio da escrita, contra a obscuridade [à] que foi relegada (Moreira, 2009, p. 68).

Com efeito, desde o prefácio de Casa de alvenaria, seu próprio "padrinho", Audálio Dantas, vaticinava sua morte como escritora: "

Agora você está na sala de visitas e continua a contribuir com este novo livro, com o qual você pode dar por encerrada a sua missão. [...] Guarde "aquelas poesias", "aqueles contos" e "aqueles romances" que você escreveu. A verdade que você gritou é muito forte, mais forte do que você imagina, Carolina (Dantas, 1961, p. 10).

A rebeldia indômita que caracterizava as aventuras da "negrinha Bitita" manifesta-se na desobediência de Carolina em aceitar o silêncio que lhe é sugerido. Contrariamente, num ato de resistência e teimosia, a reclusão no sítio camufla uma estratégia de desagravo diante da humilhação sofrida, pois a ex-catadora intensifica a atividade de escrita. Assim, retomando o projeto de "escrita de si", consideramos que o Diário de Bitita é elaborado de maneira diferenciada dos demais trabalhos com vistas a atender a um propósito específico da menina que se fez autora, afinal: "Para vencer na vida é necessário pensar e agir" (Jesus, 2016, p. 163). 
Progressivamente, vemos delinear-se a resposta de Carolina a seus detratores e à avalanche de críticas que a destituíram do status de escritora bem-sucedida:

Além da versão das memórias publicada sob o título de Diário de Bitita, há que se registrar a existência de dois outros textos publicados, que, embora editados quase uma década depois, constituem versões primárias de capítulos das memórias, reunidos no volume Cinderela negra: a saga de Carolina Maria de Jesus, intitulados Minha vida e O Sócrates africano. Estes dois textos são bastante significativos, em primeiro lugar por nos permitirem entrever o processo de escrita de Carolina, e também por lançarem luz sobre a gênese do projeto do Diário de Bitita, ilustrando perfeitamente o avanço lento e gradual dos escritos memorialísticos da autora. A partir destes dois fragmentos de memória - mais tarde retrabalhados e integrados ao Diário - podemos reunir argumentos para imaginar uma Carolina que, mesmo mudando completamente de vida, ainda dedicava boa parte de seu tempo e energia a escrever, a escrita para ela era um modo de ser, não de estar (Moreira 2009, p. 69).

Não há que se compreender a reclusão, portanto, como fuga ou evasão, mas antes como um deslocamento sagaz apto a permitir à autora reavaliar a situação, reestruturar o combate e reinventar a si própria, mergulhando no passado para melhor reconfigurar o presente. É nesse sentido que o Diário será elaborado de modo absolutamente sui generis no âmbito dos escritos carolineanos. Sabe-se que, no sítio, a escritora conta com uma ajuda bastante especial na revisão de seus originais, a da filha Vera Eunice: "pela manhã, atendia às aulas do magistério, e à tarde corrigia os escritos da minha mãe" (Lima, 1994, p. 81). Além disso, num plano mais prático, é a comparação do Diário de Bitita com esses manuscritos que nos permite supor que o texto das memórias não é uma simples retradução da versão francesa, uma vez que a edição da Nova Fronteira não dá maiores esclarecimentos sobre o assunto.

Explica-se, talvez, desse modo, a evidente divergência formal existente entre o Dário de Bitita e os escritos autobiográficos de Carolina publicados anteriormente. Se antes a regra de publicação de seus livros respeitava a escrita original agregando os desvios da norma padrão, o Diário foi revisto antes de ser entregue às jornalistas francesas ou sofreu uma adequação à norma culta durante sua preparação pela editora, pois, mesmo mantendo o estilo da autora, é flagrante sua unidade coesiva no confronto com Quarto de despejo, por exemplo.

Tem razão Moreira ao afirmar que "a autora cria uma ligação lógica entre as obras, agindo como o romancista que cria ganchos entre um capítulo e outro de seu livro para torná-lo mais atraente e mais coeso" (Moreira, 2009, p. 70).

Diário de Bitita evidencia o desejo de que as memórias sejam lidas como se pertencessem ao grupo dos outros escritos de Carolina, como se fossem uma nova parte de um conjunto mais antigo. $\mathrm{O}$ fato de a narrativa que cronologicamente antecede os diários - e, como acreditamos, prepara terreno para eles - ter sido na realidade escrito posteriormente, aponta com bastante clareza para uma busca de coerência, de globalidade, para a intenção de traçar uma linha contínua, que dê conta de toda a trajetória da vida de Carolina. Assim, temos o Diário de Bitita, em que a autora nos conta sua vida desde sua infância - recuando sempre para a história de sua família - até pouco antes de sua ida para a favela do Canindé; o período do Canindé podemos encontrar no Quarto de despejo e a ele se segue Casa de alvenaria, que busca dar conta das experiências de Carolina depois da publicação de seu primeiro livro e consequente saída da favela para habitar em sua tão sonhada casa. Como podemos notar, com a adição do Diário de Bitita ao corpo da obra de Carolina, temos um panorama completo de sua vida, o relato pessoal de toda a sua trajetória, ou uma trilogia vivencial, como chamou Meihy $(1998$, p. 159) ao conjunto das três obras. Não é inocentemente que a narrativa do Diário termina com a chegada da escritora, na época trabalhando como doméstica, na cidade de São Paulo e projetando sonhos para o futuro (Moreira, 2009, p. 70).

Nossa interpretação, todavia, visa a lançar luz sobre a reinvenção da Carolina escritora tanto no que tange à forma (ensaística) quanto aos conteúdos que veicula em seu Diário, fazendo de Bitita uma porta-voz improvável das sentenças que deseja vociferar a plenos pulmões na cara da sociedade brasileira. 


\section{As sentenças}

No Diário de Bitita, as críticas mais contundentes da narradora se apresentam sob a forma de sentenças, parábolas, aforismos e provérbios em consonância com jogos lúdicos de infância temperados pela escrita indócil, a comunicação pragmática e os juízos subjetivos tão afeitos aos ensaios modernos inaugurados por Montaigne. Nesse sentido, vários temas são privilegiados, dos quais destacaremos, por necessidade de concisão: os pretos, os pobres e as mulheres.

\section{Os pretos}

O soldado que matou o nortista era branco. O delegado era branco. E eu fiquei com medo dos brancos e olhei a minha pele preta. Por que será que o branco pode matar preto? Será que Deus deu um mundo para eles? Eu tinha excesso de imaginação, mas não chegava a nenhuma conclusão nos fatos que presenciava (Jesus, 2016, p. 116).

Carolina coloca na fala da menina Bitita uma evidência patente na compreensão dos adultos religiosos: não há a menor possibilidade de um ser perfeito como Deus ter confeccionado um mundo à parte para os brancos, o que denota uma absurda injustiça e a parábola se reveste na fórmula mais aguda, e por que não dizer, eficaz de denunciar a farsa.

Segundo Sant'Anna (2010, p. 157), a parábola encerra uma "forma narrativa curta, alegórica, que desempenha funções específicas no interior de um discurso e que constitui uma forma de épos, especialmente no corpus formado pelas parábolas de Cristo". Nesse sentido, cumpre destacar a função didático-pedagógica da narrativa parabólica e o fato de sua configuração econômica neotestamentária adaptar-se sobremodo a um diário de infância. Enquanto estratégia narrativa, possui o escopo persuasivo de influenciar de maneira direta o público receptor.

A insubmissa Carolina de Jesus brada na cara do leitor todo seu descontentamento contra o racismo, a segregação, a parcialidade, a iniquidade, as assimetrias sociais e culturais na brevidade da parábola que acolhe no seu âmago o componente metafórico, conforme admite um dos mais insignes representantes da teoria hermenêutica: "a parábola pode ser descrita como a conjunção de uma forma narrativa e um processo metafórico" (Ricœur, 1994, p. 296).

Outras parábolas somam-se no reforço dessa interpretação: “E Deus gosta mais dos brancos do que dos negros. Os brancos têm casas cobertas com telhas. Se Deus não gosta de nós, por que é que nos fez nascer?" (Jesus, 2016, p. 95). Ou quando a dona Maria Cândida usa de astúcia para explorar o trabalho infantil de Bitita, prometendo-lhe um remédio para ficar branca, outro para o seu cabelo ficar escorrido e um doutor para lhe afilar o nariz:

Pensei: "Então esses homens que trabalham aqui já foram pretos, e a fazendeira os fez ficarem brancos! E quando eu ficar com os cabelos escorridos e nariz afilado, quero ir a Sacramento para os meus parentes verem. Será que vou ficar bonita? [...] Olhei as minhas mãos negras, acariciei o meu nariz chato e o meu cabelo pixaim e decidi ficar como nasci. Eu não pedi nada à dona Maria Cândida, ela é quem usou um ardil para me espoliar. Não poderia e não deveria xingá-la, ela era poderosa. Nós dependíamos dela para viver, nos dava a terra para plantarmos. Mas roguei-lhe tantas pragas! Compreendi que ela já estava pagando com os seus filhos idiotas (Jesus, 2016, p. 136-137).

O encadeamento argumentativo evoca a gênese da matéria em discussão: "Eu pensava: ‘Meu Deus! Quem foi que começou essa questão, foi o preto ou foi o branco? Quem procurou o preto? Se foi o branco quem procurou o preto, ele não tem o direito de reclamar. O negro não invadiu suas terras, foram eles que invadiram as terras dos negros'" (Jesus, 2016, p. 62-63). Também aponta para o seu desfecho aforístico, pelo viés de uma máxima de Castro Alves: "O negro é livre quando morre" (Jesus, 2016, p. 62). 


\section{Os pobres}

O pobre não tendo condição de viver dentro da cidade, só poderia viver no campo para ser espoliado. É por isso que eu digo que os fornecedores de habitantes para as favelas são os ricos e os fazendeiros. Se eles consentissem que plantássemos feijão e arroz no meio do cafezal eu voltaria para o campo. A terra onde está plantado o café é fértil e adubada. [...] O fazendeiro tem uma atenuante: É um ladrão legalizado. [...] Atualmente, há uma minoria para trabalhar na lavoura e uma maioria para consumir. Mas o povo miúdo lutou muito para ver se conseguia viver na lavoura. São incriticáveis. O país que tem mais terras no globo é o Brasil; portanto, o nosso povo já deveria estar ajustado (Jesus, 2016, p. 141-2).

O raciocínio rigoroso da protagonista baseia-se na lógica, concebida como parte da filosofia que trata das formas do pensamento em geral (dedução, indução, hipótese, inferência etc.). A menina Bitita - ou seria mais adequado consideramos que novamente estamos diante da inteligente estratégia de uma adulta Carolina? - discute com propriedade a problemática questão da reforma agrária, no Brasil. Com efeito, a fabulação narrativa explicita a visão crítica da narradora em sentenças curtas que se entretecem expressando ora consciência política, ora inconformismo, como em: "Os homens pobres olhavam os policiais como os gatos olham os cães. Mas isto é incidência, porque o homem que é policial também é pobre, e sabe as dificuldades que o homem pobre encontra para viver" (Jesus, 2016, p. 180) e "Já estava ciente que os ricos que nascem nas cidades pequenas podem nascer nus, mas os pobres têm que nascer vestidos de paciência para suportar as ignorâncias"' (Jesus, 2016, p. 181).

Caminhando pari passu com a iniquidade, a pobreza fornece o mote de avaliação ácida diante da exploração praticada pelos ricos contra os desfavorecidos: "Nós entramos pobres na fazenda e saímos mais pobres ainda. Carpimos doze mil pés de café, e colhemos também, e não recebemos nada. Que crueldade! Nos tirar da nossa casa, nos espoliar, e nos abandonar sem um tostão" (Jesus, 2016, p. 143). Por outro lado, enquadra os desvalidos no seu nicho social garantindo a salvaguarda asséptica dos abastados:

Se o filho do patrão espancasse o filho da cozinheira, ela não podia reclamar para não perder o emprego. Mas se a cozinheira tinha filha, pobre negrinha. O filho da patroa a utilizaria para o seu noviciado sexual. Meninas que ainda estavam pensando nas bonecas, nas cirandas e cirandinhas eram brutalizadas pelos filhos do senhor Pereira, Moreira, Oliveira. [...] No fim de nove meses, a negrinha era mãe de um mulato ou pardo. [...] E o filho do senhor Oliveira, depois de farto da sedução de mocinhas pobres, decidia casar-se com a filha do senhor Moreira, porque ela era rica. Ele namorava-a com todo respeito (Jesus, 2016, p. 38-39).

Ainda que padecendo de toda sorte de humilhação imposta pelos endinheirados, os elementos de sofrimento convergem, paradoxalmente, para o estabelecimento do imperativo moral de Carolina, acolhendo pressupostos kantianos:

Eu não tenho coragem de roubar. Devo e deverei lutar para conseguir tudo com honestidade. Tinha a impressão de que alguém sussurrava nos meus ouvidos - seja honesta, seja honesta, seja honesta -, como se fosse um tique taque de um relógio. Parece que eu tinha um preceptor dirigindo-me (Jesus, 2016, p. 57).

O desrespeito ao projeto deontológico na ficção carolineana cobra seu preço: "o povo saía pelas ruas para ver o ladrão. Era como se estivesse acompanhando uma procissão. Quando o delegado soltava o preto, ele desaparecia e nunca mais voltava para Sacramento. Era um castigo moral que tinha seu efeito benéfico" (Jesus, 2016, p. 94).

\section{As mulheres}

Inicialmente, e explorada sob a forma de parábola, a ambiguidade marca certa incompreensão da narradora para com a atitude das mulheres:

Uma mulher havia mandado um rei cortar a cabeça de São João Batista. Pensei: 'As mulheres também mandam no mundo! Ah! Então eu também vou mandar, só que não 
vou consentir que cortem as cabeças dos homens. As mulheres brigam por causa dos homens, gostam de beijá-los, choram porque querem os homens e depois mandam cortar a cabeça de um homem' (Jesus, 2016, p. 27).

O sentimento mais significativo no que se refere ao trato do feminino é o desejo de assemelhar-se ao homem: "Não gosto de ser mulher! Vamos mamãe! Faça eu virar homem" (Jesus, 2016, p. 16); "Quero ter a coragem que tem o homem" (Jesus, 2016, p. 17); "Eu pensava que deveria passar por debaixo do arco-íris, para virar o homem correto para auxiliar os homens" (Jesus, 2016, p. 35); "Queria ser um homem forte para comprar um Ford" (Jesus, 2016, p. 97); "Quando percebi que nem São Benedito, nem o arco-íris nem, as cruzes não faziam eu virar homem, fui me resignando e me conformando: eu deveria ser sempre mulher. Mas mesmo semiconformada, eu invejava o meu irmão que era homem" (Jesus, 2016, p. 97).

Eivada de símbolos que dão conta da experiência humana, a narrativa fantástica de Charles Perrault, Cinderela, parece arrebatar o elã de transmutação de gênero, no Diário. Isso ocorre porque se opera uma subversão dos ideais de doçura, civilidade, encantamento e recompensa atribuídos ao feminino no celebrizado enredo infanto-juvenil. O resultado é a produção de um conto de fadas às avessas, não por acaso, protagonizado pela "Cinderela negra" Carolina: "Quando eu estava com as crianças, brincávamos de roda, contávamos as histórias de fadas. E da princesa que ia dançar no inferno, porque era namorada do diabo" (Jesus, 2016, p. 27). Mais afeita à virilidade, à resistência e à sobrevivência, Bitita percebe desde suas ações pretéritas o peso do fardo que a espreitava caso aceitasse passivamente a identidade de herança sintetizada no trinômio pobre, preta, mulher:

O Humbertinho me tomou a lima. Chorei. Ele era branco. Tinha servido no exército [...] Me dá a minha lima! Me dá a minha lima. Todos temiam-no, ele era filho do juiz. E o juiz manda prender. Ele dava vazão ao seu instinto satânico. Uma tarde, quando eu passava na frente de sua casa, ele abordou-me e me jogou várias limas no rosto, nas pernas. Que dor! Então eu xinguei: - Cachorro ordinário, ninguém aqui gosta de você [...] foram contar ao doutor Brand [que] interferiu: - Você não tem educação? - Eu tenho. O teu filho é que não tem. - Cala a boca. Eu posso te internar. - Para o seu filho fazer porcaria em mim, como faz com as meninas que o senhor recolhe? É melhor ir para o inferno do que ir para a sua casa. Doutor Brand, aqui todos falam do senhor, mas ninguém tem coragem de falar para o senhor [...] Minha mãe puxou-me: - Cale a boca, cadela! Gritei: Deixa, isso aqui é uma briga de homem com homem (Jesus, 2016, p. 32-33).

A glorificação da "Cinderela negra" não se dá, portanto, mediante o contato com príncipes encantados ou a perda de sapatinhos de cristal. É pelo reconhecimento de atos singulares, sob o escrutínio do "olhar do outro" ${ }^{1}$ que Bitita é heroicizada: "O doutor Brand disse: - Vamos parar, eu vou deixar a sua cidade. Minha mãe pegou a minha mão e levoume para casa. O povo pedia. - Não bate nela. Nem os soldados mexeram comigo. [...] Quando me viam nas ruas, as pessoas sorriam para mim dizendo: - Que menina inteligente, nos defendeu! Limpou a cidade" (Jesus, 2016, p. 34); “Oh! Bitita! Você é tão correta que deveria ter nascido homem" (Jesus, 2016, p. 35).

\footnotetext{
${ }^{1}$ Hegel mostra que é somente pela alteridade que se chega à consciência do que se é. Assim, a relação de si mesmo com a consciência nunca é uma relação imediata, é sempre uma relação mediata. Por essa razão, o outro é, para a consciência de si, um ser destinado a desvanecer como um estranho a ser "assimilado", isto é, a ser reduzido ao mesmo ou ao idêntico. Esse movimento de retorno a si mesmo, partindo da alteridade e da negação, é precisamente o que o filósofo alemão denomina de "movimento do desejo". A consciência de si é primariamente uma "consciência desejante”. A consciência de si é determinada só pela supressão do outro ser que se apresenta a ela como uma vida independente. É, portanto, em essência, desejo. O reconhecimento é, por conseguinte, uma operação bidireccional "não só na medida em que é uma operação tanto sobre si quanto sobre o outro, mas também na medida em que é, na sua indivisibilidade, tanto a operação de uma das consciências de si quanto do outro". Assim, $o$ objetivo final do desejo é o reconhecimento de si através do desejo do outro. Também para Sartre, na esteira de Hegel, o "outro" caracteriza-se como um ser "que vê" e a dimensão do ser visto distingue o "eu” do "outro", já que o indivíduo só pode negar ser o "outro" porque sabe que é visto por ele. Nessa perspectiva, todos sofrem a experiência perpétua de ser eternamente o "objeto de um olhar" e essa condição define o modo original e originário de o homem existir "sob e a partir do olhar do outro" (Sartre, 1943, cap. 3 - "Le pour autrui"; Hegel, 1986, cap. 4 - "Conscience de soi").
} 


\section{Conclusão}

A obra de Carolina Maria de Jesus ecoa como um grito de resistência e rebeldia contra o status quo do opressor que vilipendia a força criativa dos desassistidos: pretos, pobres, favelados, subalternos, anônimos e subempregados. O lápis é sua lança, a folha em branco seu desafio e sua escrita uma lâmina afiada que dilacera certezas, fazendo vacilar o universo impossível: "Quando eu não tinha nada o que comer, em vez de xingar eu escrevia. Tem pessoas que, quando estão nervosas, xingam ou pensam na morte como solução. Eu escrevo o meu diário" (Jesus, 1994, p. 170).

Menos festejado no conjunto memorialístico carolineano, o Diário de Bitita interessa à medida que nos permite entrever a estratégia da autora de responder duramente aos seus críticos implacáveis, em texto que só nos chegaria postumamente, bem como demonstra sua intenção de reorganizar, pelo interior, todo o projeto autobiográfico, trazendo à cena reminiscências de infância, ainda desconhecidas do público.

Espelho que reflete as desigualdades culturais, raciais e étnicas as quais até os dias atuais assolam e envergonham o nosso país, o Diário de Bitita chama atenção por duas razões: apresenta um contundente conteúdo de denúncia histórica, constituindo uma espécie de libelo acusatório que dá testemunho da injustiça e violência que caracterizam a vida nas favelas brasileiras; sua forma de exposição assemelha-se ao modelo ensaístico pelo didatismo pragmático baseado em parábolas, expressões, aforismos e alegorias.

Impregnado de jogos lúdicos, o caráter alegórico da prédica ensaística carolineana, da qual o leitor é capaz de haurir lições, preceitos e considerações morais, remete, por essa razão, a premissas do antigo romance filosófico. Nesse sentido, a narrativa de Bitita tangencia o território fronteiriço situado entre a metafiç̧ão e a prosa teórica, verdadeiro enigma que nos instiga ao desvelamento.

Os olhos cansados da negra Carolina permitem que o passado cumprimente o futuro num abraço apertado, cingindo 21 capítulos em 23 anos: de 1914, data do nascimento da escritora, a 1937, ano em que se encerra o Diário, marcado por sua chegada a São Paulo para trabalhar como a criada de uma professora. Ao fazê-lo, efetua a inversão simbólica de conceitos e preconceitos, subvertendo igualmente vários estigmas associados à sua condição de subalternidade. Sua literatura é assim referendada pela autonomia e pela legitimidade. Sem procuração, Carolina de Jesus restabelece a voz dos que representa, demonstrando que o campo literário também faz parte da articulação de forças que constituem a esfera social.

\section{Referências}

BERARDINELLI, Alfonso (2011). A forma do ensaio e suas dimensões. Remate de Males, Campinas, v. 31, n. 1-2, p. 25-33.

CONCEIÇÃO JÚNIOR, Jorge de Oliveira (2017). Verdade e mentira ensaística na obra de José Saramago. Dissertação (Mestrado em Letras) - Universidade Estadual do Rio de Janeiro, Rio de Janeiro.

DANTAS, Audálio (1961). Casa de alvenaria, história de uma ascensão social. In: JESUS, Carolina Maria de. Casa de alvenaria: diário de uma ex-favelada. São Paulo: Livraria Francisco Alves. p. 5-10.

HEGEL Georg Wilhelm Friedrich (2006). Phénoménologie de l'esprit. Paris, Vrin.

JESUS, Carolina Maria de (2016). Diário de Bitita. São Paulo: Sesi/SP.

LIMA, Silvio Julio (1946). Ensaio sobre a essência do ensaio. São Paulo: Saraiva \& Cia.

LIMA, Vera Eunice de Jesus (1994). Esta história é meio minha e meio de minha mãe... In: LEVINE, Robert M.; MEIHY, José Carlos Sebe Bom. Cinderela negra: a saga de Carolina Maria de Jesus. Rio de Janeiro: Editora UFRJ. p. 64-87. 
MEIHY, José Carlos Sebe Bom (1998). Carolina Maria de Jesus: emblema do silêncio. Revista USP, São Paulo, n. 37.

MEIHY, José Carlos Sebe Bom (2004). Os fios dos desafios: o retrato de Carolina Maria de Jesus no tempo presente. In: SILVA, Vagner Gonçalves da (Org.). Artes do corpo. São Paulo: Selo Negro. p. 15-53.

MOISÉS, Massaud (2001). A criação literária. São Paulo: Cultrix.

MOREIRA, Daniel da Silva (2009). Reconstruir-se em texto: práticas de arquivamento e resistência no Diário de Bitita, de Carolina Maria de Jesus. Estação Literária, v. 3, p. 64-73. Disponível em: http://www.uel.br/pos/letras/EL. Acesso em: 19 maio 2018.

RICEEUR, Paul (1994). Entre philosophie et théologie II: nommer Dieu. In: RICEEUR, Paul. Lectures 3. Aux frontières de la philosophie. Paris: Seuil.

SANT'ANNA, Marco Antonio Domingues (2010). O gênero da parábola. São Paulo: Editora Unesp.

SARTRE, Jean-Paul (1943). L'être et le néant. Paris: Gallimard.

VOGT, Carlos (1983). Trabalho, pobreza e trabalho intelectual. In: SCHWARZ, Roberto (Org.). Os pobres na literatura brasileira. São Paulo: Brasiliense. 